Fournal of Medical Genetics (1976). 13, 131-135.

\title{
A family of juvenile proximal spinal muscular atrophy with dominant inheritance
}

\author{
A. CAO, C. CIANCHETTI, L. CALISTI, and W. TANGHERONI
}

From the Departments of Pediatrics, Universities of Cagliari and Pisa, and Department of Neurology and Psychiatry, University of Cagliari, Italy

Summary. A family with juvenile proximal spinal muscular atrophy with dominant inheritance and complete penetrance is reported.

The disease occurred in three generations and showed high variations in the age of onset and progression among the affected members.

A characteristic feature was the constant involvement of facial nuclei.

Pedigree analysis of families with juvenile form or type III (Emery, 1971) of proximal spinal muscular atrophy revealed various patterns of inheritance (Emery, 1971; Zellweger, 1971). Autosomal recessive inheritance was observed in many families (Emery, 1971; Zellweger, 1971). However, a small number of families have been described, where juvenile spinal muscular atrophy was inherited as an autosomal dominant trait with complete penetrance (Magee and De Jong, 1960; Grossiord et al, 1965; Armstrong, Fogelson, and Silberberg, 1966; Garvie and Woolf, 1966; Lugaresi, Gambetti, and Giovannardi-Rossi, 1966; Gamstorp, 1967; Zellweger et al, 1972; Paunier et al, 1973) or incomplete penetrance (Wohlfart, Fex, and Eliasson, 1955; Kugelberg and Welander, 1956; Becker, 1964; Hogenhuis and Engel, 1965; Amick, Smith, and Johnson, 1966; Radu et al, 1966; Tsukagoshi et al, 1966). Finally, juvenile spinal muscular atrophy has been reported with irregular dominance, where the trait becomes phenotypically apparent only in the presence of an allelic activator gene (Zellweger, Schneider, and Schuldt 1969). The purpose of this report is to describe a kindred with juvenile proximal spinal muscular atrophy displaying an autosomal dominant transmission pattern with complete penetrance. The disease occurred in three successive generations and showed high variation in the progression among the affected members. A characteristic feature in this family was a constant involvement of facial nuclei.

\section{Family history}

As can be seen from the pedigree (Fig. 1), five members, two females (V.1, V.3) and three males (III.11, IV.11, V4), were affected. The parents of V.1, V.3, V.4 are first cousins. Cases V.1, V.3, and V.4 were examined in the University Hospital; information about III.11 and IV.11 was provided by surviving family members. Pedigree members IV.8, IV.9, IV.10, IV.12, IV.13, IV.14, IV.15, V.6, V.7, V.8, and V.9, were examined by one of us (A.C.), and did not show any evidence of neuromuscular disease. Details of the family tree were given by various family members, in particular IV.10, IV.12, and IV.14; in addition, IV.12 had photographs of many pedigree members, in particular of III.9 and III.10. The various family members interviewed, all of good cultural level, were certain that there were no other affected members elsewhere in the pedigree.

\section{Case reports}

V.1, female, 19 years old (Fig. 2). Pregnancy, delivery, and early development were normal. At the age of 6 years, difficulty in running and climbing stairs was noticed. Difficulty in whistling or puckering the lips developed at the age of 8 . Inability to walk appeared later and at 13 the patient was completely chairbound. From the age of 16 years her condition remained essentially unchanged. Physical examination took place at the age of 19 years. The patient was intelligent and co-operative. She was confined to a wheelchair, unable to walk. She sat with minimal support. There was bilateral facial weakness especially on the right side (Fig. 2). There were fasciculations and atrophy of the tongue. Wasting and weakness of velum palatinum was present. Muscular atrophy and weakness were generalized, severe, and more pronounced 
I

II

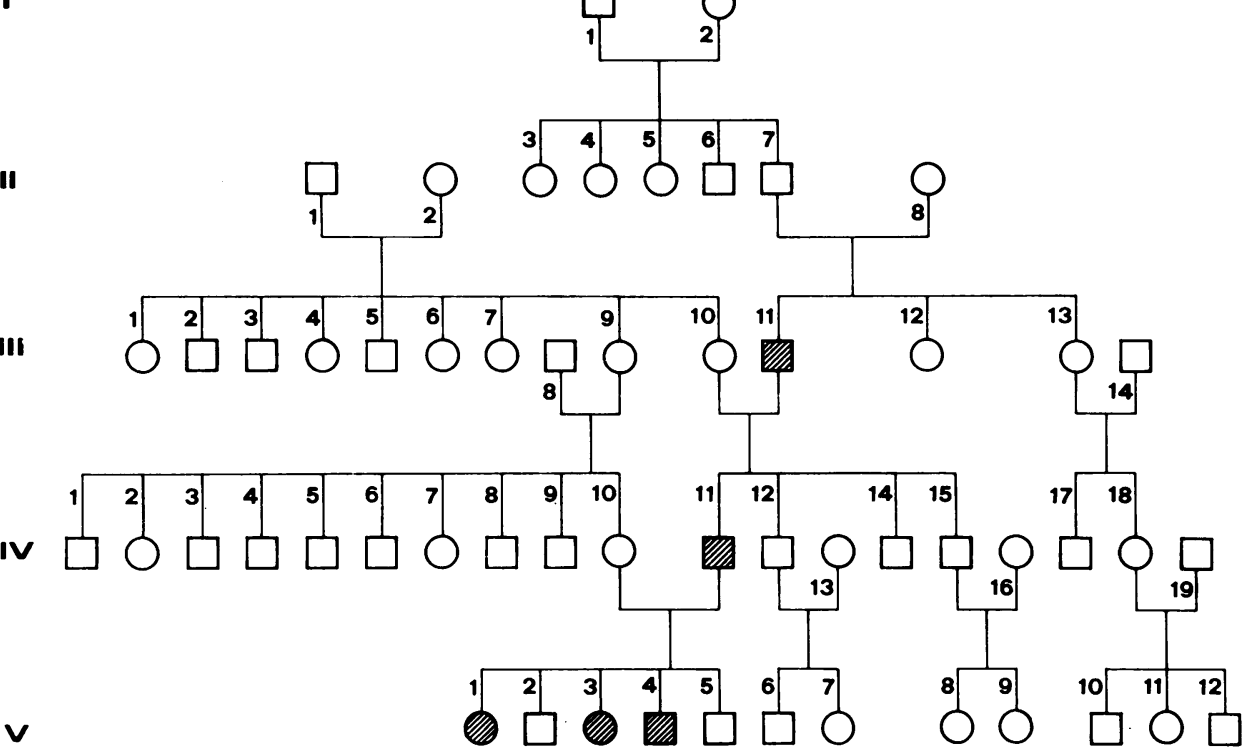

Fig. 1. Pedigree of the family.

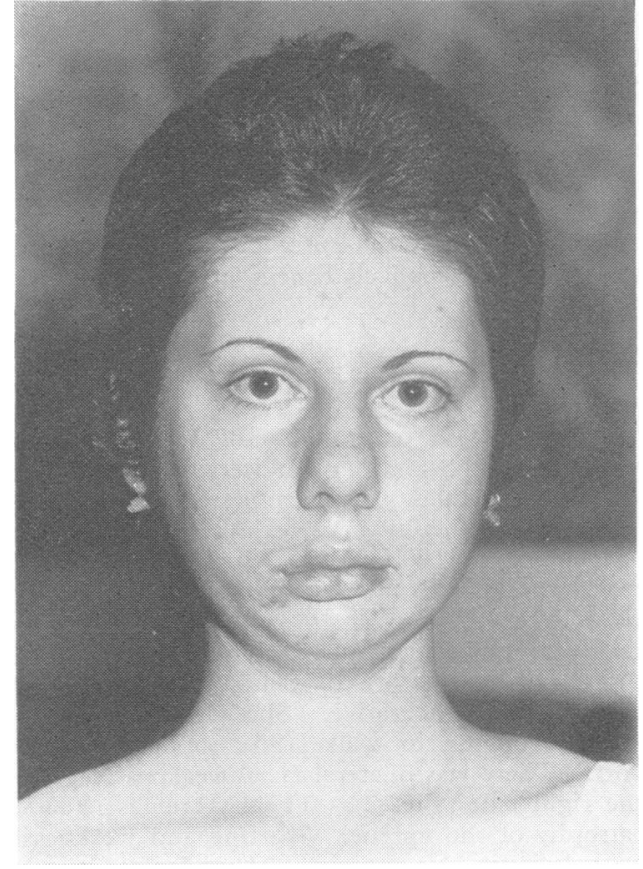

FIG. 2. Case V.1 at the age of 19 years. proximally. Deep tendon reflexes were lost. She had scoliosis, increased lumbar lordosis, pes equinovarus on the right side, and equinovalgus on the left.

Laboratory examinations including lactic acid dehydrogenase and aspartate aminotransferase were normal; creatine kinase was $55 \mathrm{mU} / \mathrm{ml}$ (normal less than $50 \mathrm{mU} / \mathrm{ml}$ ).

Electrocardiogram and electroencephalogram were normal; $x$-ray examination of the extremities showed osteoporosis.

Electromyogram showed rare denervation activity and spontaneous activity of motor unit ; no voluntary electrical activity from orbicularis oris muscle; distinct reduction of the voluntary pattern in the other muscles, with slight increase of size of motor unit potentials; normal nerve conduction time.

Muscle biopsy of the quadriceps showed atrophy (Fig. 3) and clusters of small angular fibres. In the surviving non-atrophied fascicules evidence of hypertrophy of muscle fibres was noted, with few fibres with hyaline degeneration, fibre-splitting, excessive number of internally-placed sarcolemmal nuclei, a few fibres with enlarged vescicular nuclei and prominent nucleoli, and an increase of interstitial fat and connective tissue within fascicles.

Histochemical examination (phosphorylase, myosine ATP-ase and succinic dehydrogenase techniques) showed type I grouping. The angulated fibres almost always had the histochemical properties of type I fibres.

V.3, female, 16 years old. The age of onset, progression, clinical features, and laboratory examination were similar to those of the sister V.1. Creatine kinase 


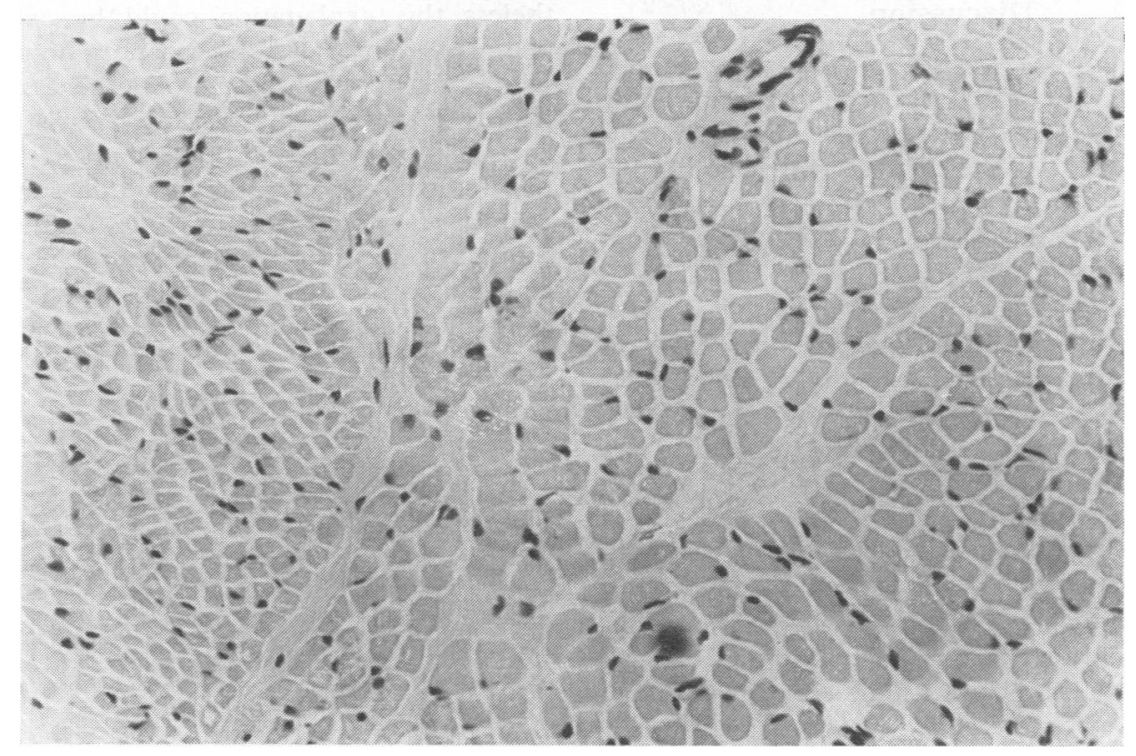

FIG. 3. Case V. 1. Quadriceps. (H. and E. $\times 25$. ) Group atrophy, angular fibres, and increase of connective tissue within fascicles.

was $24 \mathrm{mU} / \mathrm{ml}$. Electromyogram showed, in addition to the findings observed in V.1 persistent spontaneous activity of motor unit in the extensor digitorum brevis.

Muscle biopsy obtained from the vastum lateralis revealed a few groups of small fibres scattered randomly within adipose tissue.

V.4, male, 13 years old. Pregnancy, delivery, and early development were normal. At age 4 to 5 , the parents noticed that the closure of the child's eyelids was very weak on both sides. At the age of 12 , he had difficulty in rising from a sitting position, in running, and in climbing stairs. Later on, he developed inability to whistle and pucker the lips and increasing difficulty in raising his arms.

His neuromuscular condition showed a very slow progression.

Physical examination at the age of 13 years revealed a boy of normal intelligence and normal height and weight. The abnormal findings were limited to the motor system. He walked with a waddling gait, and could not squat or hop. He rose from supine position with Gowers' manoeuvre and he had slight difficulty in climbing stairs. There was bilateral facial weakness, particularly of the orbicularis oris. The muscles of the shoulder girdle and upper arms, especially the deltoids, and of the pelvic girdle and both quadriceps were weak and slightly wasted. Deep tendon reflexes were normal. There were fasciculations of the tongue. No sensory abnormalities were present. The patient had scoliosis, winged scapulas, increased lumber lordosis, and bilateral club-foot. Laboratory studies including lactic acid dehydrogenase (LDH) and serum aspartate aminotransferase (AST) were within the normal range; creatine kinase was $55 \mathrm{mU} / \mathrm{ml}$ (normal: less than $50 \mathrm{mU} / \mathrm{ml}$ ).

Electrocardiogram, electroencephalogram, and $x$-rays of the chest and extremities were normal.

Electromyography showed rare fasciculation potentials, reduced interference pattern with increase of size of motor unit potentials (amplitude until $8 \mathrm{mV}$, mean duration increased more than $20 \%$ ); normal nerve conduction velocity. These findings were more distinct in proximal and facial muscle.

Muscle biopsy of the quadriceps revealed muscle fascicles with uniform fibre size and moderate adipose replacement. Thin angulated fibres scattered randomly in fascicles of normal fibres were seen.

Histochemical examination (phosphorylase, myosin ATP-ase and succinic dehydrogenase techniques) showed predominance of type I fibres and type I grouping. The angulated fibres almost all had the histochemical properties of type I fibres.

\section{Affected relatives not examined}

IV.11. 50-year-old male pharmacist. At the age of 19 he had difficulty in running and whistling. The condition progressed slowly and at the age of 37 he climbed stairs with great difficulty. By 47 years of age he became completely chair-bound.

III.11. His disease began in childhood. The first signs were difficulty in running and whistling. He was able to walk and climb stairs until 50 years of age. At the age of 55 he was confined to a wheel-chair, and died at 64 . 


\section{Discussion}

In the present cases onset in infancy, prolonged benign course, proximal muscular atrophy with neurogenic electromyogram and muscle biopsy, strongly suggest that the disease in this family belongs to the juvenile type, or type III, of proximal spinal muscular atrophy (Wohlfart-KugelbergWelander syndrome).

In this family the abnormal gene was transmitted directly in three generations. In the progeny of the affected individuals there were four affected and six unaffected subjects. Three of the affected were male and two female. This pattern of transmission is compatible with autosomal dominant inheritance with complete penetrance. The parental consanguinity found in the family seems to be a chance occurrence.

An alternative explanation is the direct transmission, generation to generation, of a recessive trait (pseudo-dominance). This transmission pattern is found when the gene is frequent or inbreeding is intense. However in our family consanguinity occurred in only one generation and the frequency of this form of spinal muscular atrophy is rare. Moreover the family history and the examination of many members, particularly IV.10, did not show subclinical cases elsewhere in the pedigree.

The disease in the present family showed a chronic course, slow progression, and early onset similar to that of the reported cases of dominant juvenile spinal muscular atrophy with complete penetrance. The disease was more severe in female sibs than in male sibs, in contrast to the usual pattern (Namba, Aberfeld, and Grob, 1970).

A characteristic feature in the present family is the high variability of the phenotypic expression in the different members. Cases V.3 and V.1 were severely affected and became chairbound at 13 years of age, while case III.11 and IV.11 were still able to walk at 45 and 50 years of age, respectively.

In juvenile spinal muscular atrophy intrafamiliar variability is usually limited (Zellweger, 1971), but some families have been reported in which intrafamiliar variability was quite pronounced (Hogenhuis and Engel, 1965 ; Amick et al, 1966 ; Paunier et al, 1973).

The disease was more severe and led to earlier incapacity in the last generation than in the two preceding it. The most probable explanation of the greater severity in generation $\mathrm{V}$ is the so-called anticipation. An alternative interpretation is that the cases with more severe incapacity were really homozygous and the other more mildly affected were heterozygous for a dominant gene. Never- theless this explanation could be excluded since pedigree member IV.10 did not show evidence of neuromuscular disease. Another characteristic feature in this family was the consistent and precocious involvement of pontine nuclei. Bulbar and pontine palsy in juvenile and adult spinal muscular atrophy is not frequent, but an involvement of bulbar nuclei of mild degree and not progressive was also present in other reported families (Myrianthopoulos and Brown, 1954; Tsukagoshi et al, 1966; Peters et al, 1968).

\section{REFERENCES}

Amick, L. D., Smith, H. L., and Johnson, W. W. (1966). An unusual spectrum of progressive spinal muscular atrophy. Acta Neurologica Scandinavica, 42, 275-295.

Armstrong, R. M., Fogelson, H., and Silberberg, D. H. (1966). Familial proximal spinal muscular atrophy. Archives of Neuro$\log y, 14,208-212$.

Becker, P. E. (1964). Atrophia musculorum spinalis pseudomyopathica. Hereditare neurogene proximale Amyotrophie von Kugelberg und Welander. Zeitschrift für menschliche Vererbungsund Konstitutionslehre, 37, 192-220.

Emery, A. E. H. (1971). The nosology of the spinal muscular atrophies. Fournal of Medical Genetics, 8, 481-495.

Gamstorp, I. (1967). Progressive spinal muscular atrophy with onset in infancy or early childhood. Acta Paediatrica Scandinavica, 56, 408-423.

Garvie, J. M. and Woolf, A. L. (1966). Kugelberg-Welander syndrome (hereditary proximal spinal muscular atrophy). British Medical fournal, 1, 1458-1461.

Grossiord, A., Horiga, J., Paunier, S., and Gajdos, P. (1965). A propos des frontieres de la maladie de Werdnig-Hoffmann. In Proceedings of the 8th International Congress of Neurology, Vol. 2, Neuromuscular Disease, pp. 357-363. Wiener Akademie, Vienna.

Hogenhuis, L. A. H. and Engel W. K. (1965). Early onset chronic motor neuropathies : clinical and muscle histochemical studies. In Proceedings of the 8th International Congress Neurology, Vol. 2, Neuromuscular Disease, pp. 499-504. Wiener Akademie; Vienna.

Kugelberg, E. and Welander, L. (1956). Heredofamilial juvenile muscular atrophy simulating muscular dystrophy. Archives of Neurology and Psychiatry, 75, 500-509.

Lugaresi, E., Gambetti, P., and Giovannardi-Rossi, P. (1966). Chronic neurogenic muscle atrophies of infancy. Their nosologic relationship with Werdnig-Hoffmann's disease. Fournal of the Neurological Sciences, 3, 399-409.

Magee, K. E. and De Jong, R. N. (1960). Neurogenic muscular atrophy simulating muscular distrophy. Archives of Neurology, 2, 677-682.

Myrianthopoulos, M. C. and Brown, I. A. (1954). A genetic study of progressive spinal muscular atrophy. American Fournal of Human Genetics, 6, 384-411.

Namba, L., Aberfeld, D. C., and Grob, D. (1970). Chronic proximal spinal muscular atrophy. Fournal of Neurological Sciences, $11,401-423$.

Paunier, L., Pagnamenta, F., Monnard, E., Felgenhauer, W. R., Behar, A., and Moody, J. F. (1973). Spinal muscular atrophy with various clinical manifestations on a family. Helvetica Paediiatrica Acta, 28, 19-25.

Peters, H. A., Opitz, J. M., Goto, I., and Reese, H. H. (1968). The benign proximal spinal progressive muscular atrophies. A clinical and genetical study. Acta Neurologica Scandinavica, 44, 542-560.

Radu, H., Seceleanu, A., Migea, S., Torok, Z., Bordeianu, L., and Seceleanu, S. (1966). La pseudomyopathie neurogene de Kugelberg-Welander. Acta Neurologica et Psychiatrica Belgica, 66, 409-427.

Tsukagoshi, H., Nakanischi, L., Kondo, K., and Tsubaki, T. (1965). Hereditary proximal neurogenic muscular atrophy in adult. Archives of Neurology, 12, 597-603. 
Tsukagoshi, H., Sugita, H., Furukawa, T., Tsubaki, T., and Ono, E. (1966). Kugelberg-Welander syndrome with dominant inheritance. Archives of Neurology, 14, 378-381.

Wohlfart, G., Fex, J., and Eliasson, S. (1955). Hereditary proximal spinal muscular atrophy. A clinical entity simulating progressive muscular dystrophy. Acta Psychiatrica et Neurologica Scandinavica, 30, 395-406.

Zellweger, H. (1971). The genetic heterogeneity of spinal muscular atrophy. Birth Defects: Original Article Series, Vol. 7, No. 2 . pp. 82-89. Ed. by D. Bergsma. The National FoundationMarch of Dimes, New York.

Zellweger, H., Schneider, H., and Schuldt, D. R. (1969). A new genetic variant of spinal muscular atrophy. Neurology, 19, 865869.

Zellweger, H., Simpson, J., McCornick, W. F., and Ionasescu, V. (1972). Spinal muscular atrophy with autosomal dominant inheritance. Neurology, 22, 957-963. 